\title{
Assessment of Existing Bond-Slip Models of Adhesively Bonded CFRP-Steel Joints
}

\author{
Mohammed J. Altaee ${ }^{1}$, Majid M.A. Kadhim², Sarmed A.S. Altayee ${ }^{3}$ and Akram Jawdhari ${ }^{4}$ \\ $\left\{\right.$ mohammed.altaee@uobabylon.edu.iq ${ }^{1}$, majid.mohammed@uobabylon.edu.iq ${ }^{2}$, \\ eng.sarmed.salih@uobabylon.edu.iq ${ }^{3}$, akram.hassan@uky.edu $\left.{ }^{4}\right\}$ \\ Environmental Research and Studies Center, University of Babylon, Hilla, Iraq ${ }^{1}$ \\ College of Engineering, University of Babylon, Hilla, Iraq ${ }^{2,3}$ \\ Queen's University, Kingston, ON, Canada ${ }^{4}$
}

\begin{abstract}
Strengthening of steel structures with fibre-reinforced polymer (FRP) composites has attracted great attention due to their desirable mechanical properties, noncorrosive nature, and ease of application. The bond between an FRP laminate and steel substrate plays a significant role in ensuring the effectiveness of the strengthening system. Various bond-slip $(\tau-\delta)$ relations for FRP-steel joints have been developed, mainly from experimental tests on single or double-lap shear specimens. However, existing models employ different stress-slip relations and mathematical expressions, suggesting that their predictions of failure load, mode and other interface properties, might be inconsistent. In this study, a comprehensive finite element (FE) model, comprising all parts of the FRPsteel joint in a double-lap configuration, has been developed to evaluate several commonly used $(\tau-\delta)$ models. The FE model is able to capture all probable failure modes including interfacial failure (debonding), FRP rupture and steel yielding. In addition, a new trapezoidal $\tau-\delta$ law has been coded into the FE software by the authors and compared with other existing models. The FE model was then used to simulate a large number of doublelap tests from literature containing different material and geometric properties and varying by the $(\tau-\delta)$ relation from examined theoretical models. Comparisons with experimental data showed a large scatter of failure loads and joint behavior, due to difference in $(\tau-\delta)$ models. The models that best align with test results and those that deviate, were identified and discussed.
\end{abstract}

Keywords: FRP-steel joint, finite element, bond-slip model, ABAQUS, double strap joint.

\section{Introduction}

Fibre reinforced polymer (FRP) composite has been widely employed in civil engineering strengthening applications due to their excellent material properties such as resistance to harsh environment and high tensile strength. Previous studies illustrated that the use of FRP in strengthening/repair of steel members subjected to static [1-5], cyclic [6], [7] and impact loads [8], [9] offers a promising alternative to conventional rehabilitation techniques. Thus, several manuals and guidelines (e.g., [10]) have been proposed for strengthening steel structures with FRP materials. Despite the large body of research on this discipline, few studies have been conducted on the bond-slip response between FRP and steel substrate.

Analysis of FRP strengthened members are usually undertaken by analytical or finite element (FE) methods [11-18]. FE method provides a powerful tool to expand investigations 
into the effectiveness of FRP strengthening technique without the need to perform repetitive, expensive and time-consuming tests. However, use of this method in studying the bond of FRPsteel joint is conditional to using a bond-slip $(\tau-\delta)$ model capable of representing the joint's interfacial behavior and predicting the failure load. The $\tau$ - $\delta$ model is typically implemented in $\mathrm{FE}$ analysis as a material input for cohesive elements that define the interface between dissimilar parts $[13,14]$.

Several $\tau-\delta$ models have been suggested in previous research studies [19-21] to represent the bond response between FRP and steel substrate. Xia and Teng [20] model was one of the first trails in developing bond-slip model for FRP-steel joints. Another model was proposed by Fawzia et al.[19] and was developed based on a few specimens of double strap joints. Both of above models can be used for linear adhesive materials. Fernando [21] proposed two models, including a triangular (bilinear) and trapezoidal models, which can be used for linear (brittle) and nonlinear (ductile) adhesive materials, respectively.

In this research, a robust FE model has been developed for 21 FRP-bonded double-strap steel specimens tested by other researchers, constituting a wide range of geometrical and material characteristics, including a bond length (Lf) from 30 to $250 \mathrm{~mm}$; an FRP elastic modulus (Ef) from 159 to 479 GPa corresponding to normal, high and ultra-high modulus laminates; two types of adhesive, brittle and ductile (nonlinear); and three types of failure modes, namely: debonding at FRP-steel interface, FRP rupture, and delamination. The FE model was used to test the predictions of several $\tau$ - $\delta$ relations that commonly used for FRPbonded steel, by implementing each of those relations within the numerical framework and comparing the model's results with those from tests. In addition, the study developed and implemented a trapezoidally shaped $(\tau-\delta)$ model into ABAQUS software. In contrast to the linear $(\tau-\delta)$ model currently available in ABAQUS and typically implemented for brittle adhesives, the trapezoidal model can be used to accurately model the behavior of steel members bonded to FRP composites by ductile or nonlinear adhesives.

\section{Bond-slip models}

As previously mentioned, several bond-slip models proposed in the literature, to predict the bond behaviour of FRP-steel joints, have been examined in this study. While other models might be available in literature, the three above models were selected due to their popularity among research on FRP bonded steel members. The mathematical details and key parameters of each model considered in this research are listed in Table 1 . The first model in the table was developed by Xia and Teng [20] which based on experimental data of 13 single shear tests. The variables considered in the model are the adhesive type and adhesive thickness (ta). The model is bilinear in shape as can be seen in Fig. 1, with key parameters of maximum shear strength $\left(\tau_{f}\right)$, slip at maximum shear $\left(\delta_{1}\right)$, slip at complete debonding $\left(\delta_{f}\right)$, and fracture energy $\left(G_{f}\right)$. The key parameters are related to the mechanical properties of the adhesive, including its tensile strength $\left(f_{t, a}\right)$, thickness (ta), and fracture energy $\left(G_{a}\right)$. The model only considers the cohesive failure within the adhesive layer while neglecting interface debonding. 


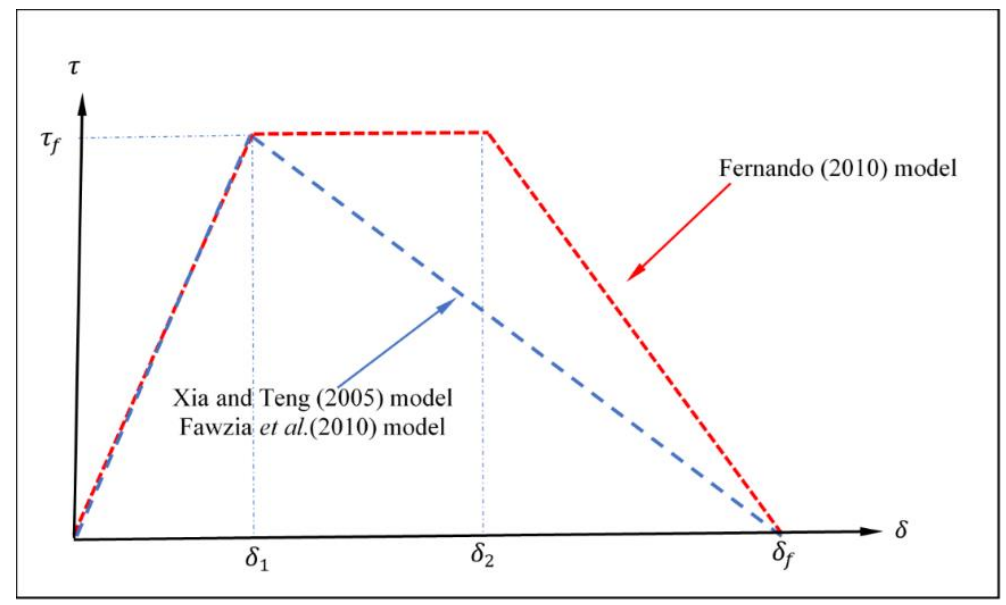

Figure 1. Bond-slip shapes of [19], [20] and [21].

The second model in Table 1, by Fawzia et al. [19] was derived from analysis 26 double shear joints tests. A number of parameters were investigated including the modulus of carbon FRP (CFRP) sheet considering two types, normal and high modulus; type of adhesive, considering three commercially available adhesive (Araldite420, MBrace saturant and Sikadur30); number of CFRP layers, either 3 or 5; and bond length (lf) ranging from 80 to $250 \mathrm{~mm}$. This model is bilinear also (Fig. 1) and dependent on the adhesive properties alone. Fernando [21] tested 18 single-shear bond specimens and developed two $\tau-\delta$ models, a bilinear and trapezoidal models, as shown in Fig. 1. The parameters examined were the adhesive type, testing four types, namely: Sikadur 30, Sikadur330, Araldite420 and Araldite 2015; adhesive thickness, trying three values for ta =1.5, 2 and 3mm; and CFRP modulus (Ef), using two values for $\mathrm{Ef}=235$ and $340 \mathrm{GPa}$.

\section{Finite element modelling}

ABAQUS software [22] was employed to model the FRP-steel double lap joints. Solid elements C3D8R were used to represent the steel plates. FRP laminates were modelled using linear threedimensional four-node shell elements with reduced integration and membrane strain (S4R). The bond region between FRP and steel was modelled using eight-node three-dimensional cohesive elements (COH3D8). Elements with mesh size of $1 \mathrm{~mm}$ were used in the bond region for all parts (steel, FRP and adhesive material) as shown in Fig 2. The mesh was then gradually increased to a maximum size of $5 \mathrm{~mm}$, for regions outside the bond area. Since the explicit solver was used in the current research which overcomes the convergence problem that normally occurs in the case of contact or material complicities, less care was paid to use smaller element size as a treatment of convergence aspects. The total number of elements for simulated joints ranged from 13544 to 6147 elements based on the bond length. 
Table 1. Details of bond-slip models from literature.

\begin{tabular}{|c|c|c|c|c|c|}
\hline $\begin{array}{c}\text { Bond-slip } \\
\text { model }\end{array}$ & $\tau_{f}$ & $\delta_{1}$ & $\delta_{2}$ & $\delta_{f}$ & $G_{f}$ \\
\hline $\begin{array}{c}\text { Xia and } \\
\text { Teng [20] }\end{array}$ & $0.8 f_{t, a}$ & $\tau_{f} \cdot t_{a} / \mathrm{Ga}$ & - & $\frac{2 G_{f}}{\tau_{f}}$ & $\frac{31}{\tau_{f}}\left(\frac{f_{t, a}}{G_{a}}\right)^{0.56} t_{a}{ }^{0.27}$ \\
\hline $\begin{array}{c}\text { Fawzia et } \\
\text { al. [19] }\end{array}$ & $f_{t, a}$ & $\frac{t_{a}}{10}$ & - & $\begin{array}{l}\frac{t_{a}}{4} \text { for } t_{a}=0.1-0.5 \mathrm{~mm} \\
=0.5-1 \mathrm{~mm}\end{array}$ & - \\
\hline $\begin{array}{c}\text { Bilinear } \\
\text { model } \\
\text { Fernando } \\
{[21]}\end{array}$ & $0.9 f_{t, a}$ & $0.3\left(\frac{t_{a}}{G_{a}}\right)^{0.65} f_{t, a}$ & - & $\frac{2 G_{f}}{\tau_{f}}$ & $628 t_{a}{ }^{0.5} R^{2}$ \\
\hline $\begin{array}{c}\text { Trapezoidal } \\
\text { model }\end{array}$ & $0.9 f_{t, a}$ & $0.081 \mathrm{~mm}$ & 0.8 & $\frac{2\left(G_{f}-\tau_{f}\left(\delta_{2}-\frac{\delta_{1}}{2}\right)\right)}{\mathrm{mm}}+\delta_{2}$ & $628 t_{a}{ }^{0.5} R^{2}$ \\
$\begin{array}{c}\text { Fernando } \\
{[21]}\end{array}$ & & $\frac{\tau_{f}}{2}$ & \\
\hline
\end{tabular}

$\mathrm{G}_{\mathrm{f}}$ : Interfacial fracture energy, $\mathrm{R}$ : the area under stress (MPa) strain curve of the adhesive material, $\tau \mathrm{f}$ : allowable shear strength of adhesive, $\mathrm{t}_{\mathrm{a}}$ : adhesive thickness, $\mathrm{f}_{\mathrm{t}, \mathrm{a}}$ : allowable tensile strength of adhesive. $\mathrm{G}_{\mathrm{a}}$ : adhesive shear modulus. $\delta_{1}$ : damage initiation of adhesive in bilinear model, $\delta_{2}$ :damage initiation of adhesive in trapezoidal model.

Due to geometrical and material symmetry of specimens in $\mathrm{x}, \mathrm{y}$ and $\mathrm{z}$ axes, only one eighth portion of the full-scale specimens was modelled. For the FRP-steel joint consists of two interfaces (FRP-to-adhesive interface and adhesive-to-steel interface), a surface-to-surface contact elements were used in either interface, along with pure master to slave contact algorithm. Due its small stiffness compared to steel and FP, the adhesive layer was assumed to be the slave surface. In addition, the adhesive layer was modelled as a discrete layer, with mechanical properties and layer thickness taken from the corresponding experimental tests. The steel plates were modelled as a linear elastic material defined by the elastic modulus (Es) and Poisson's ratio $(v)$, assuming values of Es $=200 \mathrm{GPa}$ and $v=0.3$. The linear elastic model was selected in lieu of a plasticity-based model because no yielding was reported for the steel plates in the experimental studies. FRP was modelled using a lamina model which is suitable to model unidirectional FRP composites. In order to model the rupture failure of FRP, Hashin failure criteria [23] was used as a damage initiation criteria when the laminate's stress exceeds its tensile strength. After damage initiation, the laminate stiffness is assumed to degrade to a very small value, simulating a brittle failure.

A traction-separation model is used to define the adhesive layer in ABAQUS, based on recommendations of previous research on FRP strengthened steel or concrete members [8], [1316], [18][24]. The traction-separation model contains three stages, an ascending linear stage, damage initiation in stage two, and damage progression in the last stage. In the first stage, Young's or shear moduli of the adhesive layer were divided by its thickness to obtain the stiffness of the linear elastic response in the normal and two shear directions, respectively [22]. Then, a quadratic nominal stress criterion was used to define the onset of debonding (damage) for the second stage. The quadratic criterion considers the mixed mode debonding process due to normal (peeling) and shear and is widely used in studies on FRP-steel bond problems such as 
[13], [14]. In the last stage, the interface debonding process is modelled in ABAQUS by cohesive zone model $(\mathrm{CZM})$, considering three options, a bilinear form applicable to $(\tau-\delta)$ models by Xia and Teng [20] and Fawzia et al. [19]; a trilinear form applicable to the bilinear $(\tau-\delta)$ model by Fernando [21]; and a tubular form applicable to the trapezoidal $(\tau-\delta)$ model by Fernando [21].

Numerical values for the key inputs of the traction-separation law, namely: $\tau_{f}, \delta_{1}$, and $\delta_{f}$, were obtained from the theoretical ( $\tau$ - $\delta$ ) models examined in this study using available material and geometric properties of the experimental specimen. The FE model of each double-strap specimen was run four times, according to the $(\tau-\delta)$ models examined in Table 1.

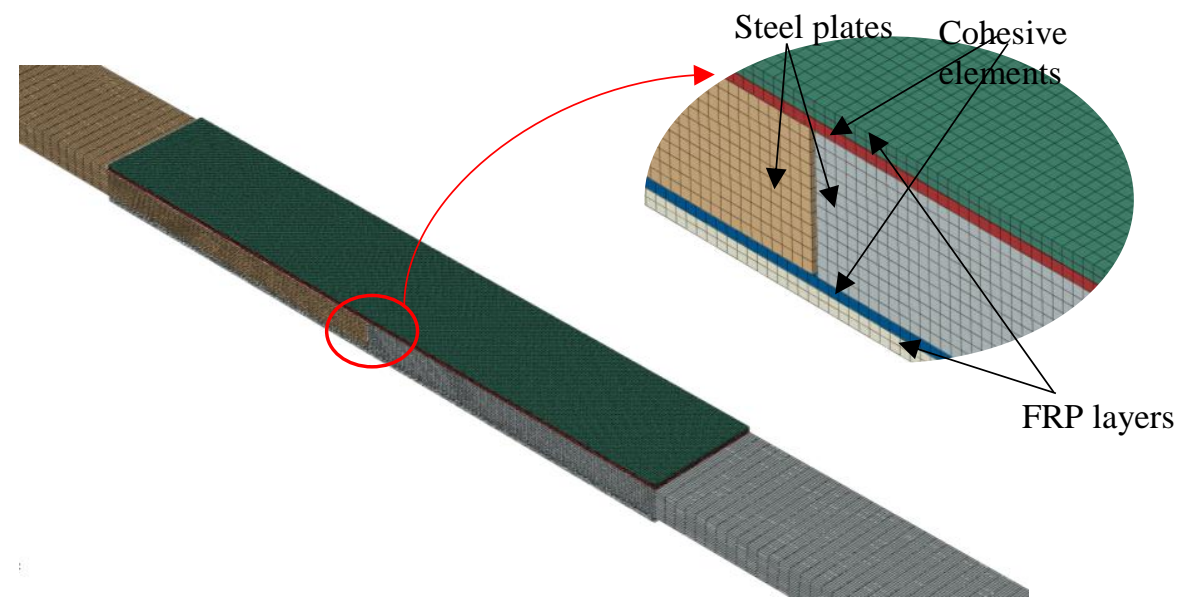

Figure 2. Typical FE model for double-strap FRP-steel joints.

\section{Summary of experiments}

To evaluate predictions of the $(\tau-\delta)$ models considered in this study, FE models were generated and compared with 21 double-strap joint tests obtained from four sets of experiments from [13], [14], [19] , and [25]. The experimental tests contained specimens with various bond lengths, bond widths, material and geometric properties for the FRP laminate and adhesive layer, as can be noticed in Table 2. The specimens were selected to assess the models' ability in capturing the behavior of different FRPs, specimen dimensions, and failure modes. Table 3 list the mechanical properties of FRP composite and adhesive layer for each experiment, as reported in the experimental research.

Table 2. Details of experimental specimens and key results summary.

\begin{tabular}{|c|c|c|c|c|c|c|c|c|c|c|}
\hline \multirow{3}{*}{ Reference } & \multirow{2}{*}{$\begin{array}{c}\text { Specimen } \\
\text { Id }\end{array}$} & \multirow{2}{*}{$\begin{array}{c}L_{f} \\
\text { mm }\end{array}$} & & \multicolumn{4}{|c|}{ Failure load (Pult.), kN } & \multicolumn{3}{c|}{ Failure mode (FM) } \\
\cline { 4 - 12 } & & $\begin{array}{c}\text { Pult- } \\
\text { exp. }\end{array}$ & $\begin{array}{l}\text { Pult- } \\
\text { FE1. }\end{array}$ & $\begin{array}{c}\text { Pult- } \\
\text { FE2 }\end{array}$ & $\begin{array}{c}\text { Pult- } \\
\text { FE3. }\end{array}$ & $\begin{array}{c}\text { FM- } \\
\text { exp. }\end{array}$ & $\begin{array}{c}\text { FM- } \\
\text { FE1. }\end{array}$ & $\begin{array}{c}\text { FM- } \\
\text { FE2. }\end{array}$ & $\begin{array}{c}\text { FM- } \\
\text { FE3. }\end{array}$ \\
\hline & S3-30 & 30 & 41.0 & 12.4 & 20.8 & 33.9 & D & D & D & D \\
\hline
\end{tabular}




\begin{tabular}{|c|c|c|c|c|c|c|c|c|c|c|}
\hline \multirow{11}{*}{$\begin{array}{c}\text { Al- } \\
\text { Mosawe } \\
\text { et al. [14] }\end{array}$} & S3-60 & 60 & 69.1 & 13.4 & 22.6 & 68.3 & $\mathrm{D}$ & $\mathrm{D}$ & $\mathrm{D}$ & $\mathrm{D}$ \\
\hline & S3-90 & 90 & 93.6 & 13.5 & 22.7 & 102.1 & $\mathrm{D}$ & $\mathrm{D}$ & $\mathrm{D}$ & $\mathrm{D}$ \\
\hline & NS-30 & 30 & 41.9 & 12.7 & 22.5 & 34.2 & $\mathrm{D}$ & $\mathrm{D}$ & $\mathrm{D}$ & D \\
\hline & NS-60 & 60 & 69.8 & 15.3 & 26.0 & 68.4 & $\mathrm{D}$ & $\mathrm{D}$ & $\mathrm{D}$ & $\mathrm{D}$ \\
\hline & NS-90 & 90 & 94.2 & 15.5 & 26.1 & 101.9 & $\mathrm{D}$ & $\mathrm{D}$ & $\mathrm{D}$ & $\mathrm{D}$ \\
\hline & UHS-30 & 30 & 31.8 & 19.2 & 29.7 & 34.2 & $\mathrm{~F}$ & $\mathrm{D}$ & $\mathrm{D}$ & $\mathrm{D}$ \\
\hline & UHS-60 & 60 & 64.1 & 22.6 & 38.4 & 57.3 & $\mathrm{~F}$ & $\mathrm{D}$ & $\mathrm{D}$ & $\mathrm{D}$ \\
\hline & UHS-90 & 90 & 73.2 & 24.6 & 41.1 & 73.2 & $\mathrm{~F}$ & $\mathrm{D}$ & $\mathrm{D}$ & $\mathrm{D}$ \\
\hline & $\mathrm{S} 2-30$ & 30 & 15.5 & 6.1 & 10.6 & 17.1 & $\mathrm{~F}$ & $\mathrm{D}$ & $\mathrm{D}$ & $\mathrm{D}$ \\
\hline & S2-60 & 60 & 27.6 & 6.6 & 11.1 & 34.0 & $\mathrm{~F}$ & $\mathrm{D}$ & $\mathrm{D}$ & $\mathrm{D}$ \\
\hline & S2-90 & 90 & 31.1 & 6.7 & 11.1 & 51.0 & $\mathrm{~F}$ & $\mathrm{D}$ & $\mathrm{D}$ & $\mathrm{D}$ \\
\hline \multirow{3}{*}{$\begin{array}{c}\text { Wu et al. } \\
{[25]}\end{array}$} & A50 & 50 & 137.2 & 59.0 & 98.7 & 141.8 & $\mathrm{~F}$ & $\mathrm{D}$ & $\mathrm{D}$ & $\mathrm{D}$ \\
\hline & A100 & 100 & 250.6 & 61.2 & 108.4 & 232.3 & $\mathrm{~F}$ & $\mathrm{D}$ & $\mathrm{D}$ & $\mathrm{F}$ \\
\hline & A250 & 250 & 267.3 & 61.6 & 109.9 & 232.3 & $\mathrm{~F}$ & $\mathrm{D}$ & $\mathrm{D}$ & $\mathrm{F}$ \\
\hline \multirow{3}{*}{$\begin{array}{c}\text { Al- } \\
\text { Zubaidy } \\
\text { et al [13] }\end{array}$} & CF-1-A-10 & 10 & 19.8 & 12.2 & 17.5 & 25.9 & $\mathrm{D}$ & $\mathrm{D}$ & $\mathrm{D}$ & $\mathrm{D}$ \\
\hline & CF-1-A-20 & 20 & 37.8 & 12.5 & 19.1 & 28.8 & $\mathrm{D}$ & $\mathrm{D}$ & $\mathrm{D}$ & $\mathrm{F}$ \\
\hline & CF-1-A-30 & 30 & 45.2 & 12.7 & 19.1 & 28.8 & $\mathrm{~F}$ & $\mathrm{D}$ & $\mathrm{D}$ & $\mathrm{F}$ \\
\hline \multirow{3}{*}{$\begin{array}{c}\text { Fawzia et } \\
\text { al. [19] }\end{array}$} & NA80 & 80 & 86.1 & 31.8 & 51.6 & 134.2 & $\mathrm{D}$ & $\mathrm{D}$ & $\mathrm{D}$ & $\mathrm{F}$ \\
\hline & NA150 & 150 & 77.8 & 31.8 & 81.1 & 136.4 & $\mathrm{D}$ & $\mathrm{D}$ & $\mathrm{D}$ & $\mathrm{F}$ \\
\hline & NA250 & 250 & 93.2 & 31.8 & 81.1 & 141.7 & $\mathrm{D}$ & $\mathrm{D}$ & $\mathrm{D}$ & $\mathrm{F}$ \\
\hline
\end{tabular}

where: $L_{f}=$ FRP bond length; Pult-exp.= ultimate load from test; Pult-FE1., Pult-FE2., and Pult-FE3. = ultimate load from FE model and using $(\tau-\delta)$ models from Xia and Teng [20], Fawzia et al. [19], and Fernando [21], respectively; FM-exp.= failure mode from test; FM-FE1., FM-FE2., and FM-FE3 . = failure mode from FE model and using $(\tau-\delta)$ models from Xia and Teng [20], Fawzia et al. [19], and Fernando [21], respectively; $\mathrm{D}=$ FRP debonding; F= FRP rupture or delamination.

Table 3. Mechanical properties of FRP and adhesive materials.

\begin{tabular}{|c|c|c|c|c|c|c|c|}
\hline \multirow[b]{2}{*}{ Ref. } & \multirow[b]{2}{*}{$\begin{array}{l}\text { Specimen } \\
\text { ID }\end{array}$} & \multicolumn{4}{|c|}{ FRP laminate } & \multicolumn{2}{|c|}{ Adhesive } \\
\hline & & $\begin{array}{l}\text { Modulus } \\
E_{f}, \mathrm{GPa}\end{array}$ & $\begin{array}{l}\text { Strength } \\
\sigma f, \mathrm{MPa}\end{array}$ & $\begin{array}{c}\text { Width } \\
W_{f}, \\
\mathrm{~mm}\end{array}$ & $\begin{array}{c}\text { Thickness } \\
t_{f}, \mathrm{~mm}\end{array}$ & $\begin{array}{l}\text { Modulus } \\
E_{a}, \mathrm{GPa}\end{array}$ & $\begin{array}{c}\text { Thickness } \\
t_{a}, \mathrm{~mm}\end{array}$ \\
\hline \multirow{4}{*}{$\begin{array}{c}\text { Al-Mosawe et al. } \\
{[14]}\end{array}$} & S3 & 159 & 2854 & 20 & 1.4 & 3.2 & 0.5 \\
\hline & NS & 203 & 2861 & 20 & 1.4 & 3.2 & 0.5 \\
\hline & UHS & 450 & 1602 & 20 & 1.2 & 3.2 & 0.5 \\
\hline & S2 & 159 & 2854 & 10 & 1.4 & 3.2 & 0.5 \\
\hline \multirow{3}{*}{ Wu et al. [25] } & A50 & 479 & 1500 & 50 & 1.45 & 1.9 & 0.36 \\
\hline & A100 & 479 & 1500 & 50 & 1.45 & 1.9 & 0.31 \\
\hline & A250 & 479 & 1500 & 50 & 1.45 & 1.9 & 0.38 \\
\hline $\begin{array}{l}\text { Al-Zubaidy et al. } \\
\text { [13] }\end{array}$ & C-F-A & 205 & 1644 & 50 & 0.18 & 2.23 & 0.5 \\
\hline Fawzia et al. [19] & NA & 640 & 2650 & 50 & 0.53 & 4.0 & 0.47 \\
\hline
\end{tabular}

\section{FE Results}

Results of FE models, generated by utilizing either of the three $(\tau-\delta)$ models examined in this study, were compared with experimental data from $21 \mathrm{FRP}-$ steel double-strap joint tests. The 
comparisons were made for ultimate load $\left(\mathrm{P}_{\mathrm{ult}}\right)$ and failure mode $(\mathrm{FM})$ as listed in Table 2. Furthermore, the results were compared in graphical forms, representing plots of $\mathrm{P}_{\mathrm{ult}}$ against bond length $\left(\mathrm{L}_{\mathrm{f}}\right)$, bond width $\left(\mathrm{W}_{\mathrm{f}}\right)$ and modulus of elasticity of FRP $\left(\mathrm{E}_{\mathrm{f}}\right)$. The following sections discuss the obtained results.

\section{Ultimate load vs. bond length}

Table 2 lists the ultimate load from experiments $\left(\mathrm{P}_{\text {ult-exp }}\right)$ and those from FE models $\left(\mathrm{P}_{\text {ult-FE}}\right)$ obtained by utilizing either of the three $(\tau-\delta)$ models discussed earlier. Fig. 3 plots the relation between the experimental and numerical $\left(\mathrm{P}_{\text {ult. }}\right)$ versus the bond length $(\mathrm{Lf})$. It can be seen from the figure, that the models by Xia and Teng [20] and Fawzia et al. [19] were unable to accurately predict Pult. for most specimens and bond lengths and their predictions were divergent from the experimental values by 13 to $83 \%$. On the other hand, the model by Fernando [21] yielded much better results in comparisons with most test points, except for few cases of divergence. Most importantly, this model was able to capture the variation of $\mathrm{P}_{\text {ult. }}$ with $\mathrm{Lf}$ for most samples and predict the effective bond length $\left(\mathrm{L}_{\mathrm{eff}}\right)$, a length at which the ultimate load becomes constant when Lf reaches a certain value. Fig. 3 (d, e) shows for experimental specimens UHS tested by Al-Mosawe et al., [14] and specimens tested by $\mathrm{Wu}$ et al., [25], $\mathrm{L}_{\mathrm{eff}}$ is 60 and $100 \mathrm{~mm}$, respectively. The FE model implementing $(\tau-\delta)$ model by Fernando [21] predicted identical values for $L_{e f f}$.

\subsection{Failure modes}

The predictive capability of the three $(\tau-\delta)$ models can be assessed by examining their predictions for the failure mode and comparing with that from the tests, as can be seen in Table 2. It can be noticed that most of models were not able to capture the failure mode correctly for all specimens. The models by Xia and Teng [20] and Fawzia et al. [19] predicted only a debonding failure, regardless of the bond length. In the experimental tests, the failure mode is typically by debonding when $\mathrm{Lf}$ is smaller than $\mathrm{L}_{\mathrm{eff}}$, and FRP rupture or delamination for larger values of Lf. This trend was only captured when the $(\tau-\delta)$ model by Fernando [21] is used, although for some specimens, the model still failed by debonding.

\subsection{Bond width}

The capability of $(\tau-\delta)$ models in capturing the effects of FRP bond width $\left(\mathrm{W}_{\mathrm{f}}\right)$ was assessed by comparing the FE models with two experimental specimens from refrence [14], specimens S2 and S3 in Table 2, corresponding to $\mathrm{W}_{\mathrm{f}}$ of 10 and $15 \mathrm{~mm}$, respectively. Fig. 4 plots the relation between $\mathrm{P}_{\mathrm{ult}}$ and $\mathrm{W}_{\mathrm{f}}$., comparing test results with those from the FE models for the three examined $(\tau-\delta)$ models. Similar to the comparison for the bond length, the model by Fernando [21] was able to simulate the effects of $\mathrm{W}_{\mathrm{f}}$, with a maximum divergence from test results by 17 $\%$. While the other two models were not able to capture $\mathrm{W}_{\mathrm{f}}$, and their predictions of $\mathrm{P}_{\mathrm{ult}}$. ranged from 50 to $85 \%$.

\subsection{FRP modulus}

Al-Mosawe et al. [14] also studied experimentally the effects of FRP elastic modulus (Ef), by testing three values, 159, 203, and $450 \mathrm{GPa}$, corresponding to three classes of moduli; normal, high, and ultra-high, respectively. In order to evaluate the capability of $(\tau-\delta)$ models in capturing the effects of Ef, the results of FE analysis from either of these theoretical models were 
compared with those from Al-Mosawe et al. [14] tests for the different values of FRP modulus. Fig. 5 plots the relation between Pult. and Ef., comparing test results with those from the FE models for the three examined $(\tau-\delta)$ models.

Similar to previous comparisons for other parameters, the model by Fernando [21] was able to simulate the effects of Ef. , with a maximum divergence from test results by $17 \%$ as was in the FRP width study and the other two models were also not able to capture Ef, and their predictions of Pult. ranged from 50 to $85 \%$. A noticeable trend from either the experimental tests or FE models corresponding to the $(\tau-\delta)$ model by Fernando [21], is seen in Fig. 4, where Pult. seems to decrease with the increase of Ef. , perhaps as a result of high stress concentrations developed in stiff laminates as noticed by other researches [6], [13].

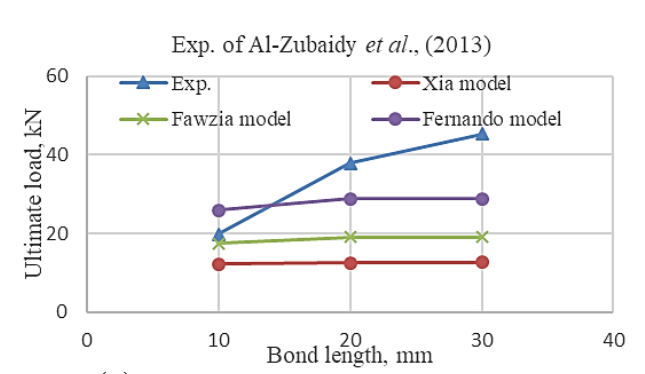

(a) Exp. of Al-Mosawe et al., (2015)

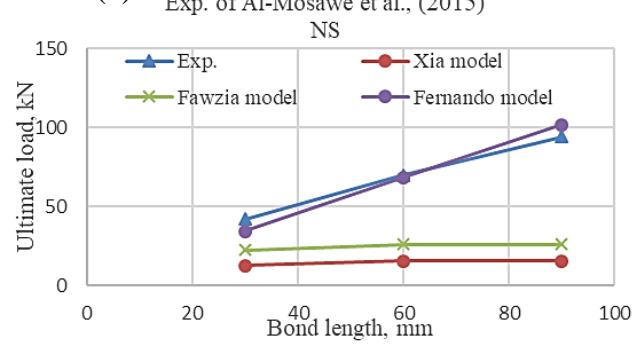

(c)

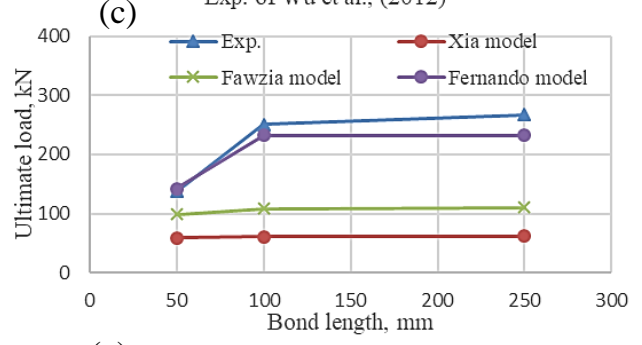

(e)

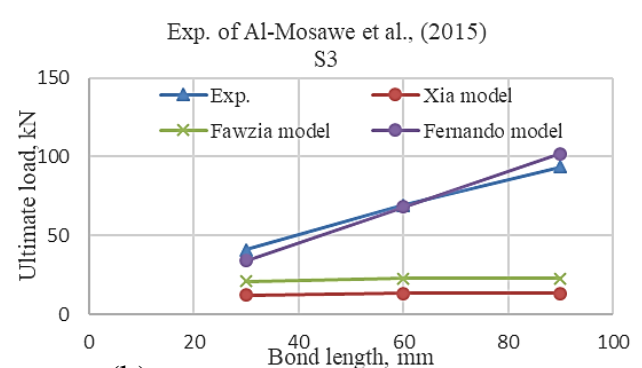

(b)
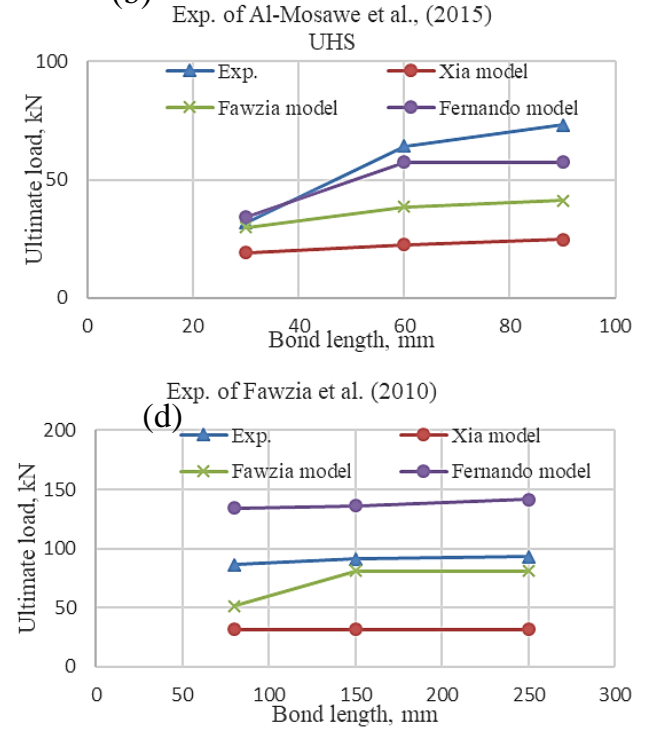

(f)

Figure 3. Ultimate load vs. bond length from tests and FE models using different $(\tau-\delta)$ models. 

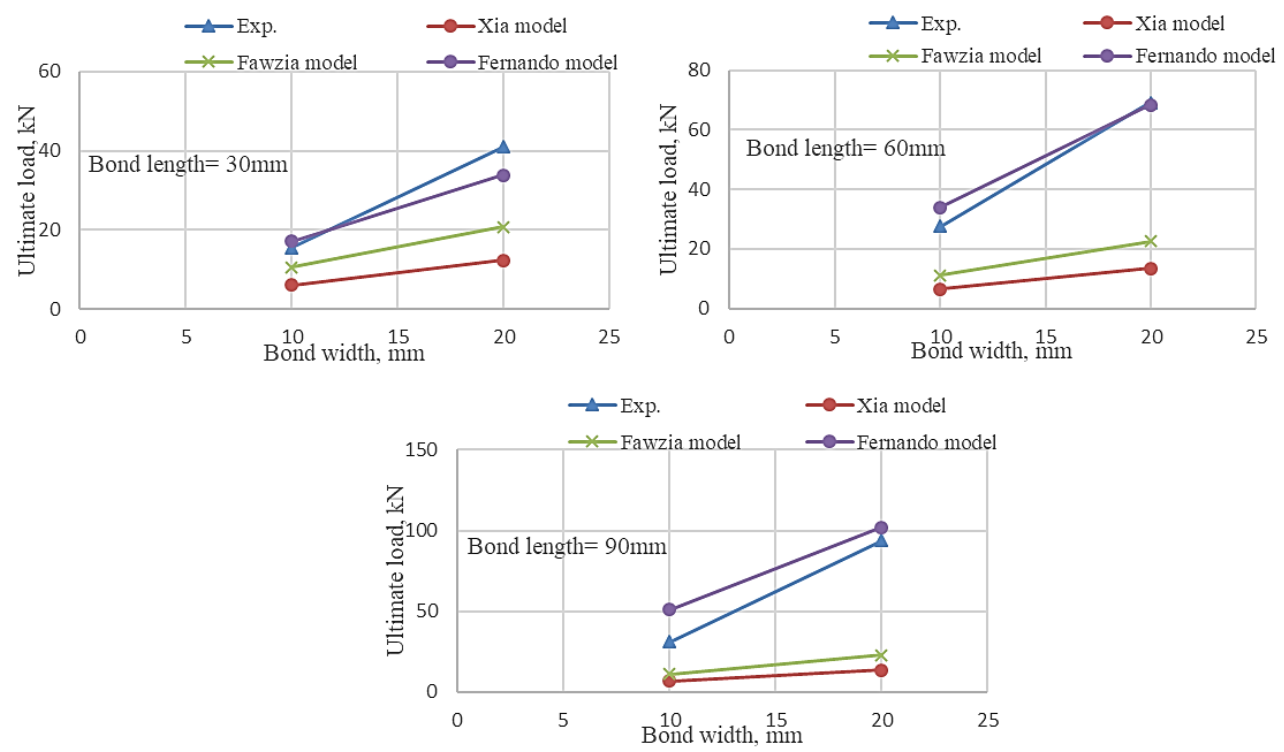

Figure 4. Ultimate load vs. bond width from tests by Al-Mosawe et al., [14] and FE models using different $(\tau-\delta)$ models.
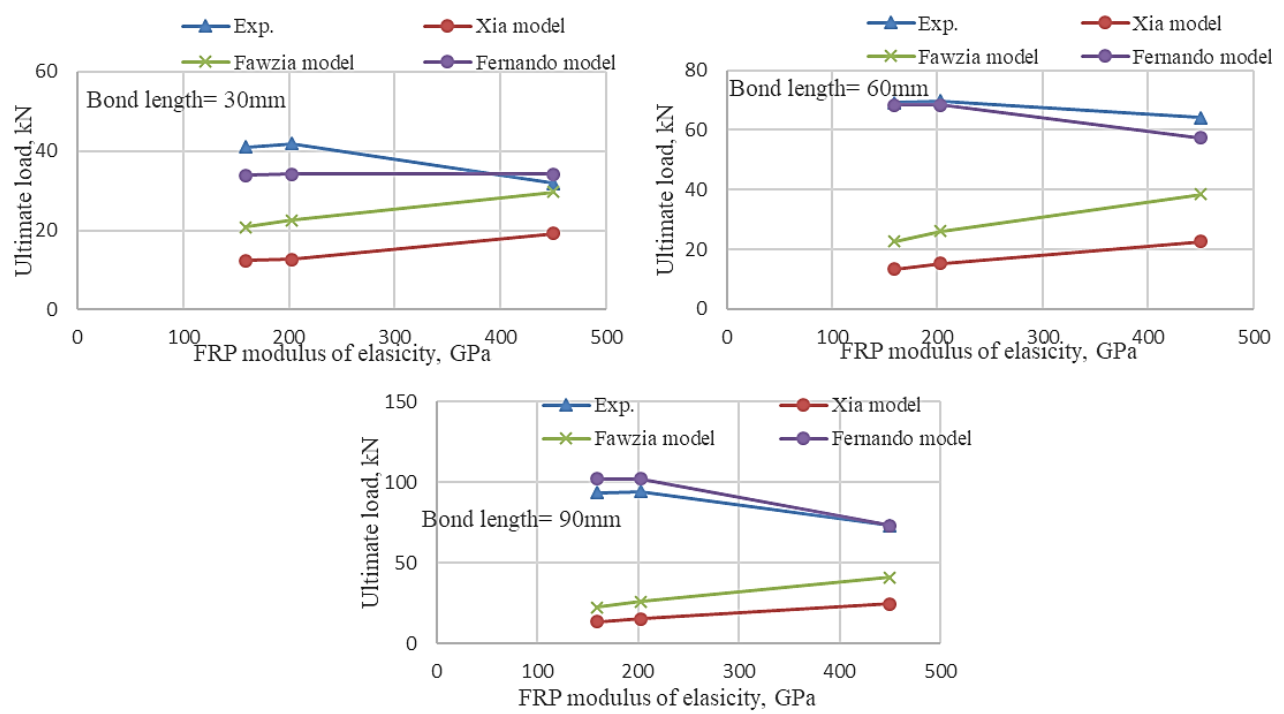

Figure 5. Ultimate load vs. FRP elastic modulus, from tests by Al-Mosawe et al., [14] and FE models using different $(\tau$-s) models. 


\section{Conclusions}

In this study, the predictive capability of three bond-slip $(\tau-\delta)$ models that widely used in literature for FRP-steel bond joints has been examined using finite element (FE) analysis. A robust FE model comprising all the joint parts and probable failure modes, was developed and compared with results from 21 double-strap FRP-steel tests from literature, constituting a wide range of material and geometric properties. Interfacial properties such as maximum shear stress and accompanying slip required for the FE model were obtained from the theoretical bond-slip models, allowing for results comparison between $(\tau-\delta)$ models and experiments, in terms of ultimate load $\left(\mathrm{P}_{\mathrm{ult}}\right)$ and failure mode. Based on the results obtained, the following conclusions can be drawn:

1. Compared to $(\tau-\delta)$ models by Xia and Teng [20] and Fawzia et al. [19], the model by Fernando [21] had much better calibrations with most test specimens in regards to $P_{u l t}$. and to capture the effects of effective bond length and the corresponding failure mode in some specimens.

2. The model by Fernando [21] was also able to capture the ultimate load when either the bond width or FRP elastic modulus were varying from 10 to $20 \mathrm{~mm}$, and 159 to 450 $\mathrm{GPa}$, respectively. The other two models were not able to simulate the effects of these two parameters.

3. A trapezoidal traction-separation relation was implements in ABAQUS software which provided an accurate representation for the bond-slip model from Fernando [21].

4. Regardless of the success seen from some of the $(\tau-\delta)$ models, much effort is still needed to develop a model capable of simulating a wide range of material and geometric variables for the FRP-steel joint.

\section{References}

[1] Deng J, Lee MMK. Behaviour under static loading of metallic beams reinforced with a bonded CFRP plate. Compos Struct [Internet]. 2007 Apr;78(2):232-42. Available from: DOI: 10.1016/j.compstruct.2005.09.004

[2] Colombi P, Poggi C. An experimental, analytical and numerical study of the static behavior of steel beams reinforced by pultruded CFRP strips. Compos Part B Eng [Internet]. 2006 Jan;37(1):64-73. Available from: DOI: 10.1016/j.compositesb.2005.03.002

[3] Kadhim MMA. Effect of CFRP plate length strengthening continuous steel beam. Constr Build Mater [Internet]. 2012 Mar;28(1):648-52. Available from: DOI: 10.1016/j.conbuildmat.2011.09.020

[4] Altaee MJ, Cunningham LS, Gillie M. Experimental investigation of CFRP-strengthened steel beams with web openings. J Constr Steel Res [Internet]. 2017 Nov;138:750-60. Available from: DOI: $10.1016 /$ j.jcsr.2017.08.023

[5] Altaee MJ, Cunningham LS, Gillie M. Experimental investigation of CFRP-strengthened steel beams with web openings. J Constr Steel Res [Internet]. 2017 Nov;138:750-60. Available from: DOI: $10.1016 /$ j.jcsr.2017.08.023

[6] Deng J, Lee MMK. Behaviour under static loading of metallic beams reinforced with a bonded CFRP plate. Compos Struct [Internet]. 2007 Apr;78(2):232-42. Available from: DOI: 10.1016/j.compstruct.2005.09.004

[7] Kim YJ, Harries KA. Fatigue behavior of damaged steel beams repaired with CFRP strips. Eng Struct. 2011;33(5):1491-502. 
[8] Kadhim M, Wu Z, Cunningham L. FE modelling of CFRP strengthened steel members under impact loads. In: Proceedings of the 24th UK Conference of the Association for Computational Mechanics in Engineering. Cardiff University Cardiff, UK; 2016. p. 343-6.

[9] Kadhim MMA, Wu Z, Cunningham LS. Experimental study of CFRP strengthened steel columns subject to lateral impact loads. Compos Struct. 2018;185:94-104.

[10] Schnerch D, Dawood M, Rizkalla S, Sumner E. Design guidelines for the use of HM strips: strengthening of steel-concrete composite bridges with high modulus carbon fiber reinforced polymer (CFRP) strips. Tech. report No. IS-06-02. Constructed Facilities Laboratory. North Carolina State University; 2006.

[11] Seleem MH, Sharaky IA, Sallam HEM. Flexural behavior of steel beams strengthened by carbon fiber reinforced polymer plates-Three dimensional finite element simulation. Mater Des. 2010;31(3):1317-24.

[12] Kadhim MMA, Mohammed MJ, Chabuk AJ. Effect of prestressed CFRP plate location on behavior of RC beam strengthened with prestressed CFRP plate. J Univ Babylon. 2012;20(1):105-13.

[13] Al-Zubaidy H, Al-Mahaidi R, Zhao X-L. Finite element modelling of CFRP/steel double strap joints subjected to dynamic tensile loadings. Compos Struct [Internet]. 2013 May;99:48-61. DOI: 10.1016/j.compstruct.2012.12.003

[14] Al-Mosawe A, Al-Mahaidi R, Zhao X-L. Experimental and Numerical Study on Strengthening of Steel Members Subjected to Impact Loading Using Ultrahigh Modulus CFRP. J Compos Constr [Internet]. 2016 Dec;20(6):04016044. Available from: DOI: 10.1061/(ASCE)CC.19435614.0000703

[15] Al Taee M, Cunningham L, Gillie M. Novel Technique for Strengthening Steel Beams with Web Penetrations. In: Proceedings of the MACE PGR Conference. Manchester: University of Manchester; 2016. p. 9-11.

[16] Al Taee M, Cunningham L, Gillie M. CFRP Strengthening of Steel Beams with Web Openings. In: Proceedings of Structural Faults \& Repair 2016: 16th International Conference. Edinburgh; 2016. p. 1754.

[17] Kadhim M, Wu Z, Cunningham L. Modelling impact resistance of polymer-laminated steelwork. Proc Inst Civ Eng Comput Mech. 2017;170(1):7-24.

[18] Altaee M, Cunningham LS, Gillie M. Practical Application of CFRP Strengthening to Steel Floor Beams with Web Openings: A numerical Investigation. J Constr Steel Res [Internet]. 2019 Apr;155:395-408. Available from: DOI: 10.1016/j.jcsr.2019.01.006

[19] Fawzia S, Zhao X-L, Al-Mahaidi R. Bond-slip models for double strap joints strengthened by CFRP. Compos Struct. 2010;92(9):2137-45.

[20] Xia SH, Teng JG. Behaviour of FRP-to-steel bonded joints. In: Proceedings of the international symposium on bond behaviour of FRP in structures. International Institute for FRP in Construction; 2005. p. 419-26.

[21] Fernando ND. Bond behaviour and debonding failures in CFRP-strengthened steel members. The Hong Kong Polytechnic University; 2010.

[22] Dassault Systèmes DS. Abaqus analysis user's guide. Technical Report Abaqus 6.14 Documentation, Simulia Corp; 2016.

[23] Hashin Z. Failure criteria for unidirectional fiber composites. 1980;

[24] Kadhim M., Adheem A., Jawdhari A., Altaee MJ., Predictive Capability of Existing Confinement Models for FRCM Composites Confined Concrete. IMDC-SDSP EAI. 2020.

[25] Wu C, Zhao X, Duan WH, Al-Mahaidi R. Bond characteristics between ultra high modulus CFRP laminates and steel. Thin-Walled Struct. 2012;51:147-57. 